\title{
Corrigendum
}

\section{Heritability of Initiation and Duration of Breastfeeding Behavior - CORRIGENDUM}

Lucia Colodro-Conde, Juan F. Sánchez-Romera, and Juan R. Ordoñana

doi: http://dx.doi.org/10.1017/thg.2013.2. Published by Cambridge University Press, 11 February 2013

The authors would like to correct the following mistakes to the abstract:

1. 'genetic factors $(0.49$ vs. 0.22 for initiation ...' should be 'genetic factors $(0.50$ vs. 0.22 for initiation ....'

2. 'heritabilities ranging from 0.39 to 0.52 in the measures studied' should be 'heritabilities ranging from 0.44 to 0.54 in the measures studied'.

\section{Reference}

Lucia Colodro-Conde, Juan F. Sánchez-Romera and Juan R. Ordoñana (2013). Heritability of Initiation and Duration of Breastfeeding Behavior. Twin Research and Human Genetics, 16, pp 575-580. doi:10.1017/thg.2013.2. 